\title{
¿Conviene seguir fomentando las forestaciones en Patagonia norte?
}

Si bien las forestaciones con especies exóticas tienen una larga historia a nivel regional, su promoción como sustento de la industria maderera se inicia a principios de la década de 1970 en Argentina, Brasil y Chile, sumándose Uruguay a fines de la década de 1990. En la actualidad, las forestaciones constituyen el núcleo de la producción forestal de éstos países, siendo una importante fuente de ingresos por exportación para Chile, Uruguay y Brasil, y habiendo reemplazado a las maderas nativas como material de construcción y muebles. La sinergia entre la producción de pulpa, madera, productos reconstituidos y energía ha potenciando el desarrollo de un sector industrial y académico asociado a las forestaciones, retroalimentando su expansión en estos países.

Estos 40 años de expansión de forestaciones comerciales han generado un creciente interés por estudiar el impacto de la introducción de especies leñosas de rápido crecimiento sobre el ciclo de agua y nutrientes, la biodiversidad de especies vegetales y animales, la dinámica de cambio de uso, cobertura y combustibilidad del paisaje y la capacidad invasora de algunas de las especies introducidas. Resultados parciales de estas líneas de investigación son utilizados cotidianamente en la definición de políticas de uso del suelo a escala local, nacional y regional. Una síntesis por parte de investigadores que centren sus estudios en el impacto ecológico, económico y social de forestaciones con especies exóticas en general y a su fomento por parte del Estado en particular brindaría una base más adecuada para la toma de decisiones por parte del Estado, propietarios y productores, generando la posibilidad de definir áreas en las que es prioritario mejorar nuestro conocimiento.

Iniciando un ciclo de foros de discusión, hemos invitado a un grupo de investigadores con larga trayectoria en la temática a iniciar dicha síntesis. Dada la diversidad de factores ecológicos y socioeconómicos asociados a un determinado uso del suelo hemos propuesto limitar el análisis a la conveniencia de promover las forestaciones en Patagonia Norte. Hace más de un siglo Bailey Willis (1914) planteaba esta necesidad como mecanismo para revertir un proceso de degradación asociado a la expansión ganadera en la región. Como introducción a las cuatro exposiciones recibidas sobre la temática, los invito a recorrer unos fragmentos de su libro "El Norte de la Patagonia":

(Acerca de la zona considerada hoy como con potencial para forestaciones) El que en estas montañas casi peladas de los Andes orientales, ve tan sólo cierta condición de clima y suelo, no podrá comprender los procesos que han producido el actual desmonte. Si ahora no se hallan estas faldas cubiertas de árboles como lo estaban antaño, ello no es debido a la escasez de la precipitación sino a la excesiva evaporación y escape... Desecadas por el escape y la evaporación rápidos, las aguas del suelo ya no eran suficientes para la renovación de los árboles, y aunque el avance de las yerbas, que señalan la conquista de los incendios, era pequeño en cualquier estación, la repetición constante ha bastado para dejar la faja casi desnuda de árboles."

(En relación al sobrepastoreo) "...se está demostrando que las plantas forrajeras pueden extinguirse si el apacentamiento es desordenado. No puede darse demasiado énfasis al hecho de que este problema debe resolverse y que la situación tiene que regularizarse debidamente para que las tierras retengan su valor y utilidad"

(Sobre lo que hoy llamamos servicios ecosistémicos) El valor del bosque remanente en Patagonia Norte..." es equivalente a la conservación de 2,000,000 de caballos de fuerza... es necesario repetir que el desenvolvimiento de la región depende de las aguas del río, y que tan benéfico factor depende a su vez de los bosques. Destrúyanse las selvas y ese benefactor se convertirá en destructor de granjas y comunidades ". (Comparando las especies leñosas del ecotono de Patagonia Norte con las de ecosistemas similares de su país) "....una vegetación de pequeños árboles retorcidos y de muchas ramas, con follaje ralo y caedizo, y crecen en matorrales pequeños.", "...entramos en los prados abiertos bajo las ramas del pino amarillo (Pinus ponderosa), entre cuyos troncos grandes y pardoscuros pacen ovejas". "La riqueza principal de las selvas de la Cordillera es su capacidad para reproducirse como mayores bosques, con las mismas especies o de otras, pero 
como bosques que constituirán imperecedera fuente de riqueza para la región." (Finalmente, nos plantea un gran desafío) "poner en práctica la selvicultura científica a cargo de especialistas... para determinar cómo habrá de efectuarse la forestación con el fin de obtener, de la nueva selva que reemplace a la antigua, el más elevado uso y las mayores ganancias. Los floresteros y selvicultores deberán ser hombres discernidores, bien adiestrados y perspicaces, porque la cosecha que ellos planten habrá de ser recolectada por la siguiente generación."

Las cuatro contribuciones de este foro abren nuevas preguntas: ¿podremos imaginar juntos cómo revertir un proceso de degradación que ya lleva más de 100 años? ¿Serán las forestaciones parte de la solución o del problema?

Las forestaciones en Patagonia se han centrado hasta hoy en el objetivo de maximizar la producción maderera, cubriendo 100,000 hectáreas en la zona de transición entre bosque y estepa. En paralelo, los bosques de ciprés y coihue, han avanzado sobre viejos incendios, matorrales y pastizales, siendo hoy importantes proveedores de productos y servicios ecosistémicos. ¿Deberíamos restringir su uso, o promover su silvicultura y manejo? ¿Existe un conflicto real entre producción, restauración y conservación, bosque nativo y forestaciones?

Agradecimientos: Este primer foro fue el resultado de charlas con Adriana Ruggiero y Esteban Jobbagy, quienes ayudaron a definir la temática y alcances del mismo. $\mathrm{Mi}$ colaboración en este foro es financiada por CONICET y el PIA 12.055.

\section{BIBLIOGRAFÍA}

Willis B. 1914. El Norte de la Patagonia. Dirección General de Ferrocarriles, Ministerio Obras Públicas de la República Argentina.

\section{Juan Gowda}

CONICET - Laboratorio Ecotono INIBIOMA Crub Uncoma

“El Comité Editorial de Ecología Austral declara que la opinión y conclusiones del foro son absoluta responsabilidad de los autores de cada trabajo y no reflejan una postura de la revista ni de la Sociedad Argentina de Ecología" 